\title{
Afrodescendentes na América Latina: da liberdade aos processos de (in)exclusão
}

\author{
Afro-descendants in Latin-America: of freedom of processes of (in)exclusion
}

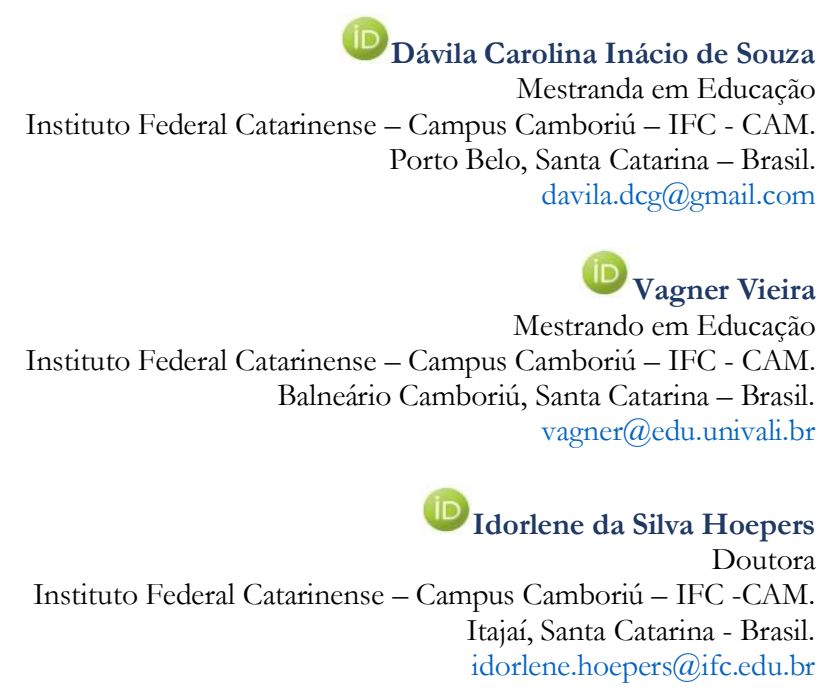

\begin{abstract}
Resumo: Com o objetivo de discutir as interferências sobre as questões étnico-raciais no contexto da América Latina e os desdobramentos para os processos de (in)exclusão da população afrodescendente, a partir dos relatórios e documentos dos organismos internacionais, realizouse estudo bibliográfico e documental. As discussões foram articuladas com Munanga (2015), Goes e Silva (2013), Sousa, (2009), Gentili (2001) e Barreto (2009), além de outros. A partir do estudo é possível perceber que, apesar de conquistar a liberdade, no contexto da América Latina, a população afrodescendente ainda sofre com as mazelas históricas que negam e invisibilizam a cultura e os aspectos históricos que provocaram tal exclusão. Nos documentos dos Organismos Internacionais encontram-se informações que ora denunciam as situações de (in)exclusão presentes na América Latina e ora fazem indicações/recomendações para desencadear pretensas ações visando os processos inclusivos dos afrodescendentes, porém alinhadas aos interesses do capitalismo.
\end{abstract}

Palavras chave: América Latina; afrodescendentes; (in)exclusão.

Abstract: In order to discuss the interferences about ethic-racial issues in the context of Latin America and the consequences of the process of (in)exclusion of Afro-descendant population, based on the reports and documents of International Organizations, it was carry out a bibliographical and documentary study. Discussion were articulated with Munanga (2015), Goes and Silva (2013), Sousa (2009), Gentili (2001) and Barreto (2009), and so on. From the study, it is possible realize that, beyond the conquer of freedom, in Latin America, the Afro-descendants population still suffer with historical ailments which denies and make invisible the culture and historical processes that make the exclusion. Documents from International Organizations it is found out information that tell us the (in)exclusion on Latin America ad makes indication/recommendation to triggering alleged actions aimed at inclusive processes of Afro-descendants, but aligned on capitalism interests.

Key-words: Latin America; african descendants; (in)exclusion.

Cite como

(ABNT NBR 6023:2018)

SOUZA, Dávila Carolina Inácio; VIEIRA, Vagner; HOEPERS, Idorlene da Silva. Afrodescendentes na América Latina: da liberdade aos processos de (in)exclusão. Dialogia, São Paulo, n. 38, p. 1-16, e20455, maio/ago. 2021. Disponível em: https://doi.org/10.5585/38.2021.20455.

American Psychological Association (APA)

Souza, D. C. I., Vieira, V., \& Hoepers, I. da. S. (2021, maio/ago.). Afrodescendentes na América Latina: da liberdade aos processos de (in)exclusão. Dialogia, São Paulo, 38, p. 1-16, e20455. https://doi.org/10.5585/38.2021.20455. 


\section{Introdução}

Ao discutir questões étnico-raciais no contexto da América Latina e os desdobramentos que levaram essa população a processos de (in)exclusão da população afrodescendente, faz-se necessária uma contextualização histórica, visto que parte dos processos vivenciados são os mesmos, como por exemplo, o fato de os países latinos americanos terem sofrido um importante apagamento histórico social, no que refere-se a população negra. Isso corrobora para que, até hoje, pessoas negras residentes em alguns países latinos ainda estejam a reivindicar o seu lugar na história e o seu lugar enquanto sujeito afrolatino na sociedade. Esta condição nos leva à seguinte reflexão: é possível que um povo que não tem a sua história contada regozije-se dos bens sociais? E mais, é possível que afrolatinos possuam os mesmos direitos educacionais que os outros? Essas são questões centrais que pretendemos abordar ao longo deste artigo.

Embora cada país possua as suas especificidades todos sofreram pela demora social em reconhecer que o ato de escravizar é um crime contra a humanidade. Esta demora fez e ainda faz com que a população afrolatina independente do país em que resida sofra dos mesmos males, que são: o racismo estrutural, o racismo recreativo, o racismo institucional, com a marginalização e sexualização de seus corpos. Tais males fazem com que, embora tenha ocorrido a abolição da escravatura, essas pessoas continuem a caminhar diariamente com o peso das senzalas.

\footnotetext{
Ainda que cada país possua suas especificidades em relação às trajetórias e percursos diaspóricos que sustentam suas estruturas e instituições, na América Latina e no Caribe existe uma rede de opressão expressa em relações de dominação baseadas em princípios, valores e ações sociais balizadas pelo ideal de embranquecimento e alicerçadas no patriarcalismo, no sexismo, no ocidentalismo e no homofobismo. O elemento comum reside na existência, nesses países, da experiência da escravização, que marcou seu processo sócio histórico [...] (SOUSA, 2009, p. 6).
}

Percebe-se que um entre tantos objetivos traçados para a população de escravos que viriam a ser libertos estava o projeto de branqueamento, que consistia em miscigenar negros e brancos, para que os frutos de tais relações possuissem uma tonalidade de pele que viesse a ser mais aceitável socialmente, ou seja, o interesse era o de por meio de misturas de raças acabar, ao longo do tempo, com os negros retintos, e assim extinguir os resquícios do processo escravocrata. Entretanto, fazse necessário enfatizar que tais miscigenações ocorreram por meio de relações não consensuais, estupros e até mesmo genocídios (NASCIMENTO, 1978).

Entretanto, torna-se importante que se reflita a respeito de quais políticas, ideologias e objetivos estavam por trás dos discursos que banalizavam os atos de torturas que feriam a dignidade 
de pessoas pretas. Como podemos observar a seguir, Vasconcelos (1948) e Freyre (1933), citados por Sousa (2009), buscavam modos de romantizar o processo escravista da América Latina.

A ideologia da mestiçagem levou o mexicano José Vasconcelos (1948), ex secretário da Educação, a defender o ideal de uma "raça cósmica", uma quinta raça resultante de todas as outras. Gilberto Freyre (1933), por outro lado, procurou minimizar ou "adocicar" a violenta relação de exploração e apropriação (os estupros) do senhor de engenho das mulheres negras e indígenas, sempre vistas como objeto do patriarca (SOUSA, 2009, p. 12).

Estes dados históricos revelados pela autora, nos mostram sob quais bases estão alicerçados os países latinos americanos, e quão necessário é investigar, escrever, pesquisar, dar vOz e visibilidade para essa parcela da população. Como afirmado anteriormente, embora já não sejam mais escravos, os afrolatinos continuam a vivenciar constantemente os desdobramentos da escravidão. O racismo estrutural continua a reforçar que essas pessoas não são pessoas que possuem direitos, tendo por vezes negado o direito à existência e a uma vida com dignidade. Munanga (2015), afirma que esse é o pior modo de se praticar racismo, pois ele está tão enraizado nas estruturas sociais e faz parte constante em nosso cotidiano, que por vezes nem se percebe que existem direitos a mais do que lhes é ofertado.

O processo de apagamento histórico da população afrolatina, por vezes ocorre por meio de instituições de ensino, que apresentam em seus currículos conteúdos históricos focados no eurocentrismo, impossibilitando um outro viés para se aprender a constituição histórica dos povos latinos desvalorizando as contribuições sociais e culturais que cada raça deu ao longo dos séculos. Deste modo, determina que a representação dos povos afrolatinos, ocorra de modo estereotipado, trazendo retratos apenas do processo escravocrata, isso quando o fazem, visto que em alguns países como Argentina e Chile, até a existência da escravidão é questionada (LOANGO; SILVA, 2017). Novamente, faz-se necessário frisar que os afrolatinos são mais do que descendentes de escravos, são pessoas que, assim como qualquer outra pessoa, trazem de seus ancestrais costumes, culturas e conhecimentos que, devido ao apagamento histórico foram impedidos de ser repassados e valorizados. Ainda conforme Adichie, 2009):

Histórias importam. Muitas histórias importam. Histórias têm sido usadas para expropriar e tornar maligno. Mas histórias podem também ser usadas para capacitar e humanizar. Histórias podem destruir a dignidade de um povo, mas histórias também podem reparar essa dignidade perdida (ADICHIE, 2009, p. 3).

A partir das evidências trazidas pelo autor, no que se refere à manutenção da história, percebe-se a necessidade que o processo histórico de constituição do povo preto latino-americano seja recontado, dessa vez com orgulho as suas ancestralidades, as suas culturas, e o principal, com 
garantia de direitos e reparações para que se tenha o mínimo de dignidade existencial após tantas torturas e mazelas, que ao menos lhes seja reservado o direito de ter voz e serem os escritores e narradores de suas histórias. Atualmente, as escritas ou falas sobre questões étnico-raciais estão perpassando pelas lutas sobre a garantia de direitos, tornando-se uma luta política e de resistência em meio aos constantes ataques e ondas de preconceitos.

Deste modo, é importante observar também o movimento que vem sendo realizado pelos organismos internacionais, os quais têm produzido uma profusão de documentos sobre as questões etnico-raciais no contexto da América Latina e seus desdobramentos para as pretensas ações inclusivas. Esta será a tarefa para a continuidade da discussão.

Os afrodescendentes a partir das lentes dos organismos internacionais na América Latina

Uma lei é válida no sentido moral quando pode ser aceita por todos a partir da perspectiva de cada um (HABERMAS, 2018, p. 80).

Após a contextualização inicial, o presente texto tem como objetivo discutir as interferências sobre as questões etnico-raciais no contexto da América Latina e os desdobramentos para os processos de (in)exclusão da população afrodescendente, a partir dos relatórios e documentos dos organismos internacionais. Por meio de estudo bibliográfico e documental cotejado por Munanga (2015), Goes e Silva (2013), Sousa, (2009), Gentili (2001) e Barreto (2009) entre outros, também foram contemplados os documentos dos organismos internacionais, a saber: Afrodescendientes y la matriz de la desigualdad social en América Latina (CEPAL, 2021), Afrodescendentes na América Latina: rumo a um marco de inclusão (GRUPO BANCO MUNDIAL, 2018), Discrimination (Employment and Occupation) Recommendation (OIT, 1958), entre outros. No entanto, para responder ao objeto do estudo, faz-se necessário compreender o que são, quais são e como funcionam os organismos internacionais.

Os organismos internacionais foram criados no período final da segunda guerra mundial, quando os Estados Unidos auxiliou países que haviam sido destruídos. Os organismos internacionais podem ser definidos como uma associação de pelo menos três Estados Nacionais, também conhecidos como países membros; não agem apenas como agências de créditos, e sim exercendo função político-estratégica fundamental nos processos de ajuste e reestruturação neoliberal (GENTILI, 2001, p. 29).

Sendo assim, pode-se dizer que o funcionamento desses organismos baseia-se em empréstimos para países tidos como periféricos ou em desenvolvimento, atuando no controle econômico, cultural e político. Ou seja, para viabilizar e efetivar esses empréstimos há, enquanto 
condição determinante, o cumprimento de exigências. Essas por sua vez expressam de modo incisivo as intenções de intervenções, no que diz respeito ao setor político de tais países.

Os organismos internacionais podem ser caracterizados por meio de quatro programas, sendo eles: Cooperação, que possui como entidades a Organização das Nações Unidas para a Educação, a Ciência e a Cultura (UNESCO) e também a Organização dos Estados Americanos (OEA); Financiamento, como o Banco Internacional para a Reconstrução e Desenvolvimento (BIRD) e o Banco Interamericano de Desenvolvimento (BID); Normativo, que possui o Acordo Geral sobre Tarifas e Comércio (GATT) e a Organização Mundial para a Propriedade Intelectual (OMPI); e o Político, como a Assembléia Geral das Nações Unidas (AGNU) e a Organização dos Estados Americanos (OEA) (SILVA, 2017).

É importante mencionar que após o fim da segunda guerra mundial, com a criação da histórica Carta das Nações Unidas, elaborada e promulgada pela Organização das Nações Unidas em 1945, em seu preâmbulo foi reafirmada a igualdade de direitos e condições entre homens e mulheres (NAÇÕES, 2007). Já em 1948 na Declaração Universal de Direitos Humanos, a ONU reafirmou, em seu Artigo $2^{\circ}$, os princípios de igualdade de qualquer espécie sem qualquer forma de discriminação (ASSEMBLEIA, 1948). A partir de então, uma série de políticas vem sendo dirigidas ao combate à discriminação racial. Pontuamos a seguir algumas dessas iniciativas históricas que visam a diminuição da exclusão étnico-racial.

Segundo Goes e Silva (2013) a construção de um regime internacional de políticas de combate ao racismo iniciou-se conjuntamente com os debates no interior dos direitos humanos, porém pautando-se nas questões relativas a esses grupos marginalizados. Assim, observou-se a construção de uma série de instrumentos jurídicos voltados para as questões raciais em muitos países, em um regime internacional de ações.

A Organização Internacional do Trabalho (OIT), órgão interno da ONU, em sua $111^{\circ}$ Convenção ocorrida em 1958, também ratificou como "cláusula pétrea", de obrigação entre seus Estados-membros, o combate às desigualdades, inclusive racial, nos seguintes termos:

\footnotetext{
Para os fins da presente Convenção, o termo "discriminação" compreende: a) toda distinção, exclusão ou preferência fundada na raça, cor, sexo, religião, opinião política, ascendência nacional ou origem social, que tenha por efeito destruir ou alterar a igualdade de oportunidades ou de tratamento em matéria de emprego ou profissão (ORGANIZAÇÃO, 1958, p. 01).
}

$\mathrm{Na}$ sequência, uma série de medidas de organismos internacionais, destacadamente a Convenção Americana de Direitos Humanos, conhecida como Pacto de San José da Costa Rica, sob Organização dos Estados Americanos (OEA), ocorrida na Costa Rica em 1969, em seu Artigo 
$1^{\circ}$, estabelecia a obrigação dos Estados-membros em respeitar os direitos e liberdades, sem qualquer discriminação (CONVENÇÃO, 1969). Ainda, o Protocolo Adicional de 1988, desta referida conferência, estabelecia em seu Artigo $3^{\circ}$, a "Obrigação de Não Discriminação" (CONVENÇÃO, 1988, p. 03).

Conforme Goes e Silva (2013) uma importante ação no combate às desigualdades raciais no campo da educação, foi a realização da Convenção contra a Discriminação no Campo do Ensino, aprovada pela ONU no ano de 1960. No entanto, desde 1948, havia solicitações por parte da Organização das Nações Unidas para a Educação, a Ciência e a Cultura (UNESCO), no sentido de elaborar diretrizes e ações com o objetivo de combater preconceitos raciais no espaço educacional e científico. As autoras pontuam, que diferentemente da Convenção n ${ }^{\circ} 111$ da OIT, a da UNESCO foi além por apresentar inovações no contexto de discriminação, por exemplo, incluir fatores como o linguístico, condições de nascimento e econômicas como discriminações a serem combatidas.

Alinhadas a estas primeiras ações, normativas e políticas de inclusão vêm sendo desenvolvidas por parte dos Estados nacionais com orientação de organismos internacionais multilaterais. $\mathrm{Na}$ América Latina, onde as relações raciais são marcadas por profunda desigualdade social, esses organismos internacionais têm produzido documentos indicando necessidades de elaboração de políticas específicas que contemplem, pelos Estados, as populações historicamente excluídas e marginalizadas. No que concerne aos afrodescendentes latino-americanos, podemos encontrar medidas direcionadas à inclusão social por parte de muitos desses organismos.

Entre tais iniciativas, há, por exemplo, a empreendida pelo Grupo Banco Mundial que publicou em 2018 um relatório sobre a condição dos afrodescendentes na América Latina, intitulado: "Afrodescendentes na América Latina: rumo a um marco de inclusão". Este relatório traz um esboço social dos afrolatinos, entendendo que a pobreza e a exclusão não afetam todos os latino-americanos da mesma maneira e que "[...] os afrodescendentes ainda apresentam taxas mais altas de pobreza que a população branca e mestiça”" (GRUPO, 2018, p. 27). Deste modo, organizou um quadro geográfico e social, cujo propósito estava em “[...] entender melhor quem são os pobres e os vulneráveis, bem como saber por que tantos latino-americanos ficaram para trás durante uma década de crescimento excepcional” (GRUPO, 2018, p. 27).

Os aspectos elencados no relatório partiram da pergunta: o que constitui historicamente os afrodescendentes latino-americanos e onde vivem? A partir deste questionamento foi elaborado o levantamento sobre o acesso ao mercado e aos bens de consumo, além de um capítulo dedicado ao acesso dos afrolatinos à educação. Mesmo que a educação básica já tenha sido universalizada, 
na maioria dos países, observa-se que os afrodescendentes apresentam níveis mais baixos de escolaridade e maior possibilidade de não concluírem o ensino fundamental quando relacionados com a população branca. O relatório destaca que "A ausência de financiamento público, a inadequação das instalações e materiais didáticos e a falta de apoio aos professores são outros fatores que limitam o desempenho de jovens e crianças afrodescendentes em toda a região" (GRUPO, 2018, p. 91).

A Comissão Econômica para a América Latina e o Caribe (CEPAL), também publicou, em 2020, um documento especialmente desenvolvido para as populações negras da América Latina, denominado: "Afrodescendentes e a matriz da desigualdade social na América Latina: desafios para a inclusão". O objetivo desse documento está em: “[...] apresentar o panorama mais atualizado possível das desigualdades que a população afrodescendente experimenta na América Latina em âmbitos importantes do desenvolvimento e dos direitos, como a incidência da pobreza e o acesso a infraestrutura básica" (COMISSÃO, 2020, p. 05). Entre os temas destacados, o documento cita a educação, saúde, trabalho docente e proteção social.

No capítulo dedicado aos aspectos de exclusão relacionados a educação, o documento pontua que, quanto ao acesso à educação básica, em todo o território latino-americano é possível perceber, nas últimas três décadas, uma maior participação dos grupos historicamente excluídos e marginalizados, como negros e indígenas. O relatório pontua também as dificuldades da permanência que, conforme a idade dos estudantes aumenta, principalmente no ensino secundário, continua apresentando índices elevados de evasão, mas também destaca que no ensino terciário, o acesso universal ainda não é garantido e, por isso, ainda excludente.

No que tange às políticas educacionais, são evidenciadas propostas que partem de uma lógica econômica, onde a relação custo benefício é quem define as prioridades de investimento no que refere-se a área educacional. Atualmente diversos autores, a exemplo de (BARRETO, 2009; EVANGELISTA e SHIROMA, 2006; LEHER, 1999a, 1999b; LIMA, 2001) entre outros, tecem críticas em seus estudos a respeito dos organismos internacionais e as suas interferências nas políticas educacionais, visto que por vezes a sociedade não passa por processo reflexivo, pois tais políticas são impostas, o que leva a uma falsa sensação de inclusão, além do fortalecimento das iniciativas privadas (BARRETO, 2009).

Nesta perspectiva, a educação passou a ser um direito garantido por meio de constituições, e consta em muitos acordos internacionais, considerando que por meio da educação seria possível alcançar maior igualdade social e a construção de sociedades mais justas, igualitárias e democráticas, que tendo estes pilares como centrais visam alcançar a inclusão das mais diversas minorias 
existentes. Percebe-se ainda, que a educação é um dos meios existentes para que se consiga diminuir os índices de pobreza, o fim do trabalho infantil e, deste modo, a educação se mostra efetiva para outras demandas sociais e direitos (CEPAL, 2017b, 2018a, 2019a).

Nas últimas décadas são perceptíveis os avanços na questão educacional na América Latina, com diminuição de índices de analfabetismo, maior número de jovens matriculados no ensino médio, e o acesso ao ensino fundamental como um direito universal. Entretanto, a população afrolatina continua sofrendo com as disparidades e, embora enfrentem questões parecidas em diferentes países, existem situações heterogêneas, que fazem com que cada país tenha as suas especificidades para lidar, com tais disparidades que atingem também o âmbito educacional, impondo mais uma barreira com a qual a população afrolatina precisa lidar.

Ao assumirem o compromisso de promover e garantir o acesso educacional para todos, os países latinos-americanos, têm se esforçado para diminuir o abismo social e educacional entre os afrolatinos e a população branca. Estes esforços, de certo modo auxiliam no reconhecimento de que os afrolatinos enfrentaram um processo de escravidão, negação de direitos, e que, além de precisarem lidar com questões relacionadas advindas do preconceito racial, ainda lidam com questões que dizem respeito a sobrevivência, como renda, saúde, entre outros.

Independente do país da América Latina a ser estudado, percebe-se, que referente a população afrolatina, as semelhanças são fruto do processo escravagista e de apagamento histórico social. É possível afirmar que os afrolatinos são os que mais evadem do âmbito escolar, e isso se deve aos fatores sociais, culturais e econômicos, visto que desde muito cedo crianças e jovens negros contribuem de forma ativa para a composição da renda familiar. Para além, precisam se dividir entre estudos e outras tarefas, não existindo por vezes a possibilidade de se concentrar somente nos estudos, o que acarreta na dicotomia quando negros precisam decidir entre trabalhar e ter com o que se alimentar ou estudar. Percebe-se também que as jovens mulheres são as que mais evadem, para auxiliar nos afazeres domésticos, cuidar de irmãos mais novos e até mesmo devido a gravidez precoce (CEPAL, 2021).

O Ensino Médio representa um divisor de águas entre os jovens pois, quando negros evadem pelos mais diversos motivos, os brancos continuam a dar continuidade em sua trajetória escolar, o que provoca novamente demarcações das diferenças sociais entre ambos. Deste modo, se perpetuam as condições excludentes dos afrolatinos no que se refere às mais diversas formas de exclusão social e preconceitos (TRUCCO, 2014).

A Comisión Económica para América Latina y Caribe (CEPAL) divulgou no ano de 2018 um gráfico com dados referentes a seis países latinos, sendo eles: Brasil, Colômbia, Equador, Panamá, 
Peru e Uruguai, com o objetivo de evidenciar as disparidades existentes entre jovens afrodescendentes e os não afrodescendentes de faixa etária de 20 a 24 anos, que completaram a educação secundária. As disparidades podem ser observadas na figura 1, a seguir:

Figura 1 - Proporção de Jovens de 20 a 24 anos que completaram a educação secundária em seis países da América Latina

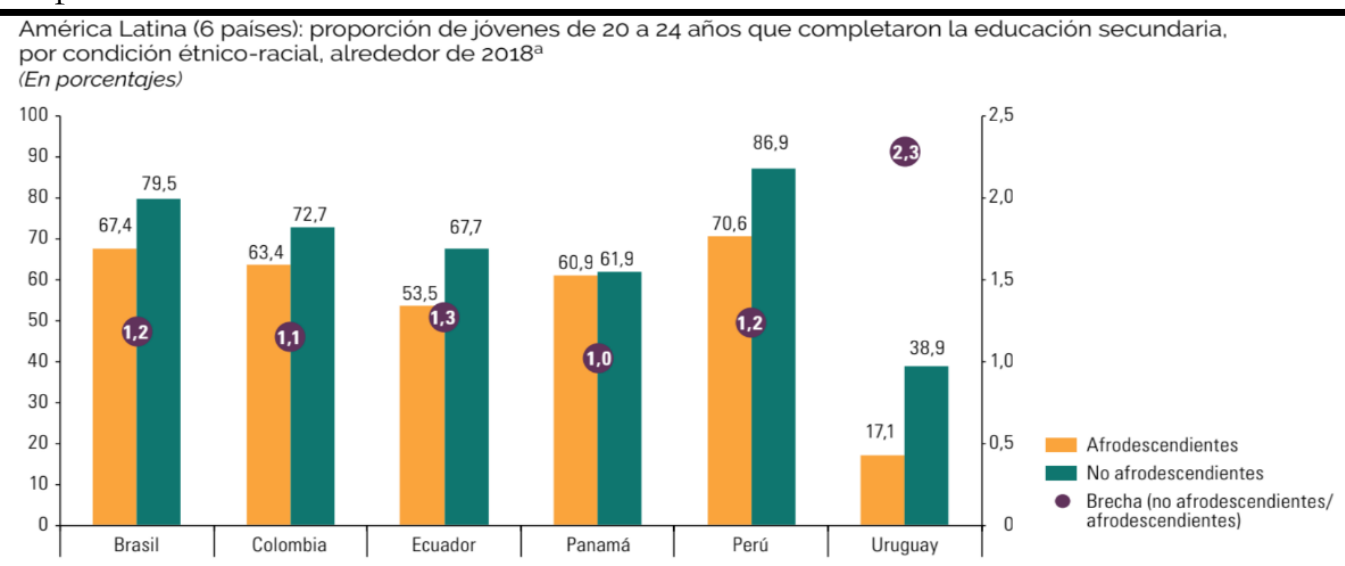

Fuente: Comisión Económica para América Latina y el Caribe (CEPAL), sobre la base de Banco de Datos de Encuestas de Hogares (BADEHOG).

Nota: En la población no afrodescendiente no se incluye la que se autoidentifica como indígena ni los casos en que se ignora la condición étnico-racial.

"Los datos del Brasil, Colombia, Panamá, el Perú y el Uruguay corresponden a 2018 y los del Ecuador a 2017.

Fonte: Gráfico retirado no formato de imagem do relatório Afrodescendientes y la matriz de la desigualdad social en América Latina (CEPAL, 2018).

Entre os países elencados na figura 1, cinco evidenciaram as desigualdades, sendo o Panamá a exceção. Ao analisar os dados percebe-se que o Uruguai é o país com maior desigualdade, evidenciando que o número de jovens brancos que concluíram a educação secundária é 2,3 vezes maior do que o número de jovens negros que concluíram esta etapa da educação.

Quando observados os dados referentes ao Brasil, Colômbia, Equador e Peru percebe-se que embora ainda existam discrepâncias no âmbito acadêmico, no que diz respeito aos jovens negros e brancos esses índices estão em queda, sendo no Brasil essa diferença de 1,2; na Colômbia de 1,1; no Equador de 1,3 e no Peru de 1,2. Considerando o contexto brasileiro é possível atribuir esse aumento de jovens negros que concluem o Ensino Médio às políticas públicas e benefícios sociais disponibilizados pelo governo em parceria com os estados, municípios e instituições de ensino.

A Comisión Económica para América Latina y Caribe (CEPAL) também apresentou no ano de 2018, dados referentes ao Ensino Superior no Brasil, Colômbia, Equador e Peru, com o objetivo de discutir se assim como na educação secundária, as desigualdades entre raça e gênero se faziam presentes conforme a figura 2 , a seguir: 
Figura 2 - Proporção de Jovens que completaram o Ensino Superior em quatro países da América latina

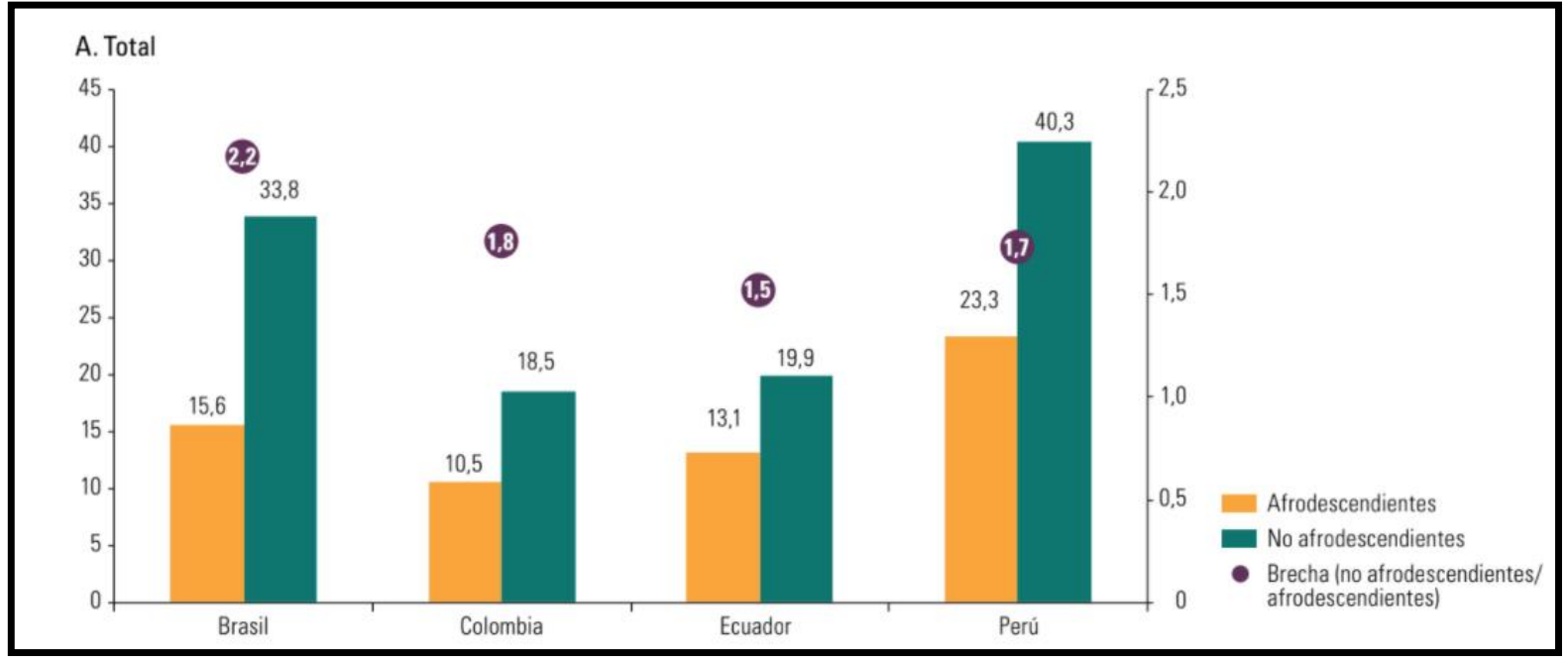

Fonte: Gráfico retirado no formato de imagem do relatório Afrodescendientes y la matriz de la desigualdad social en América Latina (CEPAL, 2018).

Quando se trata do Ensino Superior no Brasil, Colômbia, Equador e Peru, os dados mostram que em 2018 o índice de conclusão entre os jovens negros eram baixos, sendo que na Colômbia apenas 10,5\% e no Peru 23,3\% dos estudantes negros haviam concluído o Ensino Superior. Entretanto, os dados mais alarmantes foram registrados no Brasil, onde apenas 15,6\% dos jovens negros conseguiram concluir o Ensino Superior, enquanto que os jovens brancos concluíntes foram 33,8\%. Sobre os índices brasileiros cabe uma breve análise a respeito da política pública de ações afirmativas, a saber a Lei n. 12.711, promulgada no Brasil a partir do ano de 2012, em um contexto conturbado, com reivindicações de movimentos sociais favoráveis e contrários à sua adoção.

A Lei n. 12.711 é reconhecida no contexto latino-americano como referência, devido a sua abrangência e também por ter passado por um longo processo de discussão antes de ser aprovada.. Entretanto, os dados divulgados pela CEPAL no ano de 2018, mostram-nos que, no contexto brasileiro, embora tenha-se uma lei que é efetiva para o acesso de jovens negros a universidades, a mesma não garante o direito a permanência, contribuindo para que continue a predominar na vida desses jovens, a dicotomia entre formação ou mundo do trabalho visando a sobrevivência. Deste modo, pode-se afirmar que embora a lei de cotas brasileira seja importante para o acesso, há necessidade de repensá-la, objetivando dessa vez a permanência, para que esses jovens possam não só ingressar, mas também concluírem seus estudos. 
Entre os motivos que levam um jovem a evasão, muitos podem ser citados, pois depende da perspectiva de quem observa. Para alguns, pode ser por falta de competência, pelo não pertencimento ao ambiente acadêmico, ou, conforme descreve com precisão, Carvalho (2002):

[...] o professor não se questiona por que todos os seus escassos alunos negros se sentam na última fileira das cadeiras; por que ele nunca "ouve direito" quando eles falam e os força a repetir suas observações; porque automaticamente conta que não entenderam bem a matéria e antecipa que sua exposição não estará entre as melhores. E por que os colegas brancos do aluno também partem do mesmo princípio de que os negros não têm a mesma competência que eles? Assim surgem as fugas da sala de aula, as inadaptações, os mal entendidos, os climas de desconforto e as reações psicossomáticas comuns entre os estudantes negros universitários: voz baixa, mutismo, afasia, embaraço, dislexia frequente, irritação excessiva. Um conjunto de sintomas que desembocam muitas vezes no trancamento de matérias, desistências e finalmente, em abandono de cursos. A tudo isso, os professores brancos assistem indiferentes; ou quando chegam a perceber algum caso particular, não têm elementos analíticos socializados para equacionar a crise do aluno negro (CARVALHO, 2002, p. 96).

A partir das constações do autor, percebe-se que os motivos que levam um jovem negro a evadir do âmbito educacional são muitos. Por isso é importante o olhar inclusivo da Instituição de Ensino e seus servidores visto que, a lei n. 12.711 é a teoria e precisa de pessoas capazes de se libertar de amarras de estereótipos e preconceitos para fazer com que ela funcione na prática. Por meio da figura 3, a seguir, nos será possível observar que, embora historicamente as mulheres tenham sido privadas do direito de estudar, e tenham a representação social enquanto figura frágil, independente do fator racial, são a maioria na conclusão do Ensino Superior. Especificamente sobre as mulheres negras que tiveram, inclusive, a sua representação social fragilizada e negada, fazendo-se forte séculos após séculos (CARNEIRO, 2001), estes dados nos levam a inúmeras reflexões a respeito da representação social da mulher negra na América Latina. Neste sentido, a figura 3 destaca as diferenças de acesso relacionadas ao gênero. 
Figura 3 - Proporção referente ao gênero, de Jovens que completaram o Ensino Superior em três países da América latina

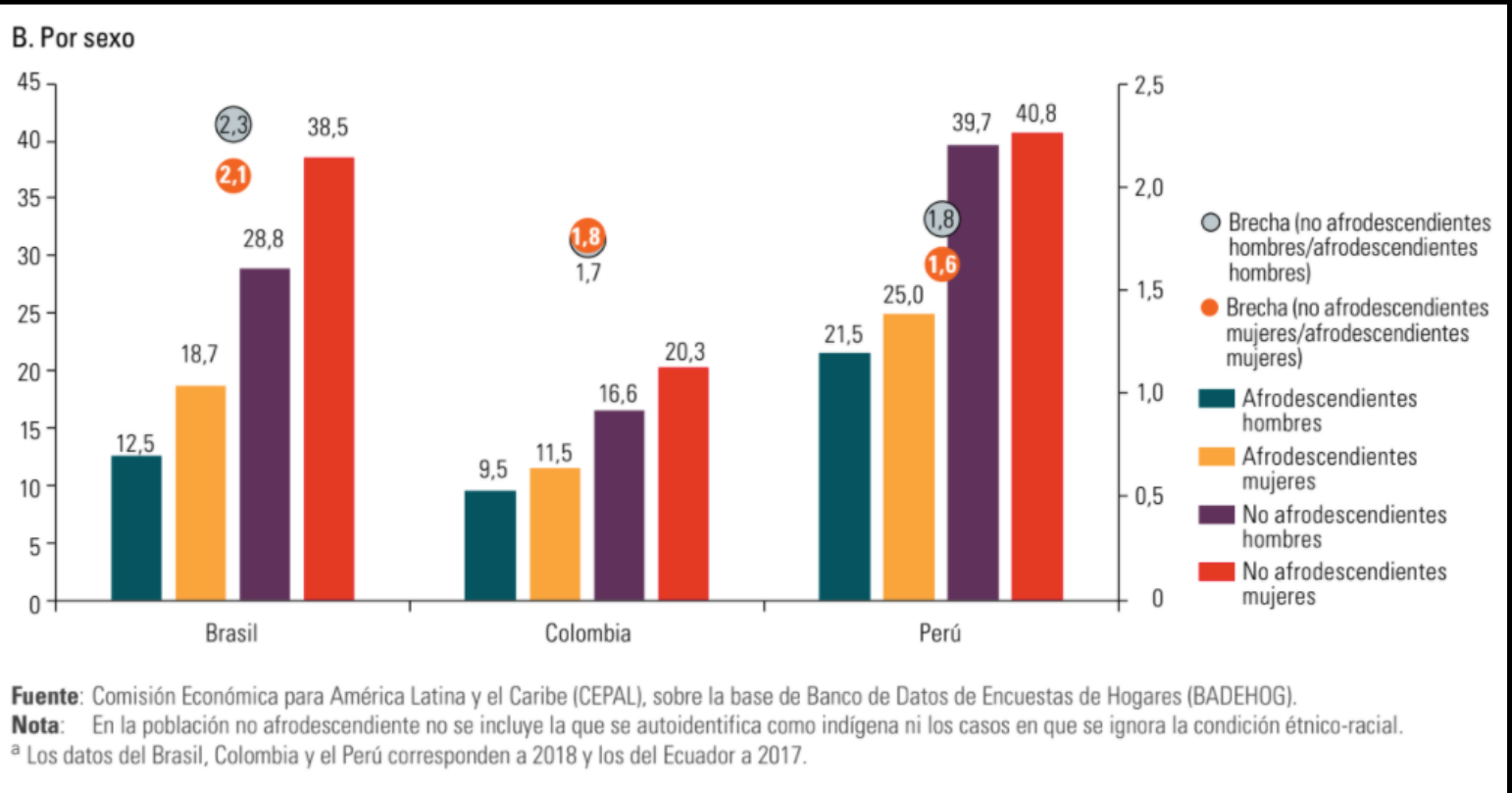

Fonte: Gráfico retirado no formato de imagem do relatório Afrodescendientes y la matriz de la desigualdad social en América Latina (CEPAL, 2018).

Quando considerado o recorte por gênero, percebe-se que no Brasil, Colômbia e Peru, as jovens do sexo feminino possuem índices melhores se comparadas com jovens do sexo masculino. No contexto brasileiro o índice de mulheres negras que concluem a graduação é de 18,7\% enquanto os índices que representam os homens negros são de $12,5 \%$. No entanto, ao tencionar as opressões sofridas pelas mulheres negras Carneiro (2001) afirma:

As mulheres negras tiveram uma experiência histórica diferenciada que o discurso clássico sobre a opressão da mulher não tem reconhecido, assim como não têm dado conta da diferença qualitativa que o efeito da opressão sofrida teve e ainda tem na identidade feminina das mulheres negras. Quando falamos do mito da fragilidade feminina, que justificou historicamente a proteção paternalista dos homens sobre as mulheres, de que mulheres estamos falando? Nós, mulheres negras, fazemos parte de um contingente de mulheres, provavelmente majoritário, que nunca reconheceram em si mesmas esse mito, porque nunca fomos tratadas como frágeis. Fazemos parte de um contingente de mulheres que trabalharam durante séculos como escravas nas lavouras ou nas ruas, como vendedoras, quituteiras, prostitutas... Mulheres que não entenderam nada quando as feministas disseram que as mulheres deveriam ganhar as ruas e trabalhar (CARNEIRO, 2003, p. 1-2).

Deste modo, percebemos que embora o fator gênero seja de extrema importância, esses dados referentes às mulheres negras brasileiras concluintes do Ensino Superior, merecem destaque, visto que, são as que estão mais suscetíveis a violências, e as que mais foram privadas de exercerem 
seus direitos educacionais ao longo da história. Se comparado com outras décadas é inegável o avanço e esse se deve às políticas públicas de ações afirmativas.

Entretanto, percebe-se que ainda assim elas continuam a ser insuficientes, visto que boa parte desses jovens vem de um contexto familiar com renda per capita por vezes inferior a um salário mínimo e meio. Esta condição afeta mais diretamente os jovens de sexo masculino, visto que a nossa sociedade possui sua estrutura alicerçada no racismo e patriarquismo contribuindo para que homens sintam-se responsáveis pela manutenção de seus lares desde muito cedo, não havendo deste modo, espaço para os estudos.

Por meio dos dados discutidos ao longo do texto, percebe-se a importância das ações afirmativas, e o quanto elas ainda se fazem necessárias, e o principal, a necessidade de ser revista para que ocorra a implementação de políticas de permanência. Nesse contexto, torna-se importante discutir o que os países latinos têm feito desde a abolição da escravatura para que os afrolatinos possam ter direitos educacionais garantidos e quais medidas de permanência são adotadas e se poderiam ser melhoradas e ou ampliadas, a partir dos dados apresentados pela Cepal (2018).

\section{Considerações Finais}

Apesar dos esforços por parte dos Estados e governos em criar políticas públicas direcionadas aos grupos historicamente marginalizados na América Latina, através dos relatórios elaborados pelos organismos multilaterais, pode-se perceber que entre negros e brancos ainda há significativas disparidades no acesso e permanência de estudantes negros, principalmente na educação secundária e terciária/superior. Porém, há que se destacar também a importância de determinadas políticas aplicadas como, por exemplo, as das cotas raciais para o acesso desses estudantes, principalmente no ensino superior. As últimas décadas têm demonstrado que os resultados obtidos são reveladores do potencial dessas ações.

É, portanto, necessário um contínuo amadurecimento das políticas de acesso à educação, em todos os níveis, especialmente nos países latino-americanos, como fator decisivo para diminuirmos a histórica desigualdade social, marca característica de exclusão de grupos étnicoraciais entre esses países. A constatação de que houve o apagamento da história da população afrodescendente no contexto latino americano, requer que sejam repensadas as formas pelas quais os processos reparatórios são colocados em curso em sociedades altamente excludentes. Apesar de conquistar a liberdade na via da legislação, sabe-se que de fato, a igualdade de condições de acesso e permanência aos diversos espaços sejam eles sociais, econômicos ou culturais, ainda não se 
efetivaram conforme foi amplamente discutido no decorrer deste texto. Os processos de (in)exclusão continuam presentes.

A fixação das lentes para os documentos produzidos pelos organismos internacionais, notadamente Banco Mundial e Cepal, não significa que as questões históricas envolvidas na criação de tais instituições tenha sido olvidada. Os interesses corporativos que estiveram presentes na época da criação se perpetuam e se fortalecem. Deste modo, considera-se imprescindível que estas discussões sejam aprofundadas, uma vez que a lógica instalada continuamente está alinhada aos processos de (in)exclusão da população afrodescendente latina que busca pela reparação histórica. Ou seja, a lógica do capital e do mercado também está presente na produção dos relatórios aqui discutidos, uma vez que auxiliam nas definições e prioridades dos investimentos educacionais nos países periféricos.

\section{Agradecimentos}

Agradecemos a CAPES E UNIEDU pelo financiamento desse artigo, por meio de bolsas de mestrado para Dávila Carolina Inácio de Souza e Vagner Vieira.

Reitera-se que o presente trabalho foi realizado com apoio da Coordenação de Aperfeiçoamento de Pessoal de Nível superior - Brasil (CAPES).

Contando também com apoio do Programa de Bolsas Universitárias de Santa Catarina (UNIEDU).

\section{Referências}

ADICHIE, Chimamanda. O perigo de uma história única. São Paulo: Companhia das Letras, 2019.

ASSEMBLEIA, Geral das Nações Unidas. Declaração Universal dos Direitos Humanos. Resolução 217 A III, 1948. Disponível em: https://www.unicef.org/brazil/declaracao-universal-dos-direitoshumanos. Acesso em: 15 jul. 2021.

BRASIL. Lei n. 12.711/2012. Dispõe sobre o ingresso nas universidades federais e nas instituições federais de ensino técnico de nível médio e dá outras providências. Disponível em: http://www.planalto.gov.br/ccivil_03/_ato2011-2014/2012/lei/112711.htm. Acesso em: 20 maio 2021.

BARRETO, Raquel Goulart. Discursos, tecnologias, educação. Rio de Janeiro: EDUERJ, 2009.

CARNEIRO, Sueli. "Enegrecer o Feminismo: A situação da mulher negra na América Latina a partir de uma perspectiva de gênero" in Racismos Contemporâneos. Org: Ashsoka /Takano Ed, Cidadania, Rio de Janeiro, 2003. 
CARVALHO, José Jorge. Exclusão racial na universidade brasileira: um caso de ação não negativa. In: QUEIROZ, Delcele Mascarenhas de. (coord.) O Negro na Universidade. Programa a Cor da Bahia / Programa de Pós-Graduação em Ciências Sociais da Faculdade de Filosofia e Ciências Humanas da UFBA. Salvador: Novos Toques, n. 5, 2002.

COMISIÓN, Económica para América Latina y el Caribe (CEPAL). (2017b), Situación de las personas afrodescendientes en América Latina y desafíos de politicas para la garantía de sus derechos.

Documentos de Proyectos (LC/TS.2017/121), Santiago.

COMISIÓN, Económica para América Latina y el Caribe (CEPAL). (2018), Panorama social de América Latina. (LC/PUB.2019/ 3-P), Santiago.

COMISIÓN, Económica para América Latina y el Caribe (CEPAL). (2018a), Hacia una agenda regional de desarrollo social inclusivo: bases y propuesta inicial (LC/MDS.2/2), Santiago.

COMISIÓN, Económica para América Latina y el Caribe (CEPAL). (2019a), Nudos críticos del desarrollo social inclusivo en América Latina y el Caribe: antecedentes para una agenda regional (LC/CDS.3/3), Santiago.

COMISIÓN, Económica para América Latina y el Caribe (CEPAL). (2020), Desvelando desigualdades estructurales en América Latina: las personas afrodescendientes y el COVID-19. Santiago

COMISSÃO, Econômica para a América Latina e o Caribe (CEPAL). Afrodescendientes y la matriz. de la desigualdad social en América Latina. Santiago, 2021, p. 26. Disponível em:

https:/ / www.cepal.org/es/publicaciones / 46191-afrodescendientes-la-matriz-la-desigualdadsocial-america-latina-retos-la. Acesso em: 20 maio 2021.

CONVENÇÃO Americana de Direitos Humanos. Pacto de San José da Costa Rica. 1969.

Disponível em:

http://www.pge.sp.gov.br/centrodeestudos/bibliotecavirtual/instrumentos/sanjose.htm Acesso em: 15 jul. 2021.

CONVENÇÃO Americana de Direitos Humanos. Protocolo adicional à convenção americana sobre direitos humanos em matéria de direitos econômicos, sociais e culturais. 1988. Disponível em:

https://direito.mppr.mp.br/arquivos/File/protocoloadicional.PDF. Acesso em: 15 jul. 2021.

EVANGELISTA, Olinda; SHIROMA, Eneida. Educação para o alivio da pobreza: novo tópico na agenda global. Revista de Educação Puc-Campinas, Campinas, n. 20, p. 43-54, Jun. 2006.

GENTILI, Pablo. A falsificação do consenso: simulacro e imposição na reforma educacional do Neoliberalismo. Vozes: Petrópolis, 2001.

GOES, Fernanda Lira; SILVA, Tatiana Dias. O Regime internacional de combate ao racismo e à discriminação racial. Rio de Janeiro: Ipea, 2013.

GRUPO Banco Mundial. Afrodescendentes na América Latina: Rumo a um marco de inclusão, 2018. Disponível em: https://dds.cepal.org/redesoc/publication?id=5034. Acesso em: 20 maio 2021.

HABERMAS, Jürgen. A inclusão do outro: estudos de teoria política. São Paulo: Editora Unesp, 2018. 
INTERNATIONAL Labour Organization. Discrimination (Employment and Occupation) Recommendation. Genebra, 1958. Disponível em:

https://www.ilo.org/dyn/normlex/en/f?p=NORMLEXPUB:12100:0::NO::P12100_ILO_COD E:R111. Acesso: 10 jul. 2021.

LEHER, Roberto. Para fazer frente ao apartheid educacional imposto pelo Banco Mundial: notas para uma leitura da temática trabalho-educação. Trabalho e Crítica. Anuário do GT Trabalbo e Educação da ANPEd. EDUFF/NETE-UFMG, set. 1999a.

LEHER, Roberto. Um Novo Senhor da Educação? A política educacional do Banco Mundial para a periferia do capitalismo. Outubro, São Paulo, v. 1, n. 3, p. 19-30, 1999 b.

LIMA, Kátia. Organismos internacionais: o capital em busca de novos campos de exploração. In: NEVES, Maria Lúcia Wanderley (org.). O empresariamento da educação: novos contornos do ensino superior no Brasil dos anos 1990. Rio de Janeiro: Xamã, 2001.

LOANGO, A.; SILVA, M. Afrodescendientes y educación superior. Un análisis de las experiencias, alcances y desafíos de las acciones afirmativas en Colombia y Brasil. In. MATO, D. Educación Superior y Sociedad Carbe: Instituto Internacional de Unesco para la Educación Superior en América Latina y el Caribe, 2017. p. 131-156.

MUNANGA, Kabengele. Porque ensinar a história da Africa e do negro no Brasil de hoje? Revista do Instituto de Estudos Brasileiros, 2015 n. 62. p. 20-31.

NAÇÕES Unidas. Carta das Nações Unidas (1945). Rio de Janeiro: Centro de Informação da ONU, 2007. Disponível em: https://brasil.un.org/pt-br/91220-carta-das-nacoes-unidas. Acesso: 15 jul. 2021.

NASCIMENTO, Abdias. O genocídio do negro brasileiro: o processo de um racismo mascarado. Rio de Janeiro: Paz e terra, 1978.

ORGANIZAÇÃO Internacional do Trabalho. Convenção no 111: Discriminação em matéria de emprego e ocupação. Genebra, 1958. Disponível em:

https://www.ilo.org/brasilia/convencoes/WCMS_235325/lang--pt/index.htm. Acesso em: 13 jul. 2021.

SILVA, Andréa. Organismos internacionais: os discursos cepalinos e o fetiche tecnológico. Trabalho necessário. Ano. 15, n. 27/2017.

SOUSA, Andréia Lisboa. Educação e Igualdade na América Latina e Caribe: A questão da discriminação racial. Campaña Latinoamericana por el Derecho a la Educación (CLADE), 2009, p. 06.

TRUCCO, Daniela. Educación y desigualdad en América Latina. Serie Políticas Sociales, $\mathrm{N}^{\circ} 200$ (LC/L.3846), Santiago, 2014, Comisión Económica para América Latina y el Caribe (CEPAL). 